\title{
Gender Differences in Perceiving Advertising Texts
}

\author{
Rouzanna Arakelyan, Margarita Sahakyan \\ Yerevan State University
}

T $\mathrm{t}$ would not be an exaggeration to say that today we live in an era of advertisment.

Nearly everyone in the modern world is to some degree affected by advertising and other forms of promotion. Although few people admit to being greatly influenced by ads, surveys show that a well-designed advertising campaign has dramatic effects. A logical conclusion is that advertising works even below the level of conscious awareness and it works even on those who claim immunity to its verbal and non-verbal messages. As the main purpose of advertising is to attract attention, arouse interest and stimulate sales, its textual message is thought over thoroughly. The language of advertisment should be pure but complicated, soft but ordering, clear but full of expressive devices, the word order should be both complex and simple, in other words, the language should be used to attract the attention of a reader, listener or viewer at once. This could be done also by appealing to emotions through arousing feelings of love, fear or pleasure.

The main persuasive goal of ads is to strengthen or change one's attitude toward a certain product or service. So it is not by chance that many advertisers use more than one technique in attemting to persuade consumers. To make the advertisment more effective, one should know for whom the advertisment is created, thus creation of ads should be carried out taking into account gender differences of consumers as well. Difficulties in differentiating gender roles in modern societies can be a perfect example of the social effects of using stereotypes. A division of gender roles is deeply rooted in the social and cultural archetypes.

Men and women perceive the reality and respond to it differently, so gender has a significant impact on the way we communicate. Men are highly visual by nature and more likely to absorb the total picture, wheras women are more detail oriented. It is not by chance that women require a clear product or pocket of text for their eyes to land on, while men will respond to the given images instantaneously. So, men and women are capable of enjoying the same advertisments, but they are likely to respond to and perceive ads differently. And since the process of perception of ads differs, the length of time men and women need to analyze the ad also varies. Studies have shown that women are able to retain more information from a 30 -second spot than men do. But women are able to retain more information from ads, they also need to see a commercial several times to be convinced to try a product or service. Therefore, women also require more information before making purchasing decisions.

Men tend to be oriented to the present and the visual, they don't require more information before making purchasing decisions and so will respond more effectively than women to seeing an ad just one time. One more distinctive feature: men have greater propensity to ads featuring humor, distinctive creative styles and a different type of imagery, while women enjoy ads featuring children or a "slice of life". In other words, men are prone to intellectual and intriguing ads, while women are prone to emotional 
appeals that border on family and children. And all the above mentioned does not come as a surprise: we often begin life with gendered identities. We communicate our gender identity and popular culture tells us what it means to be man or a woman. For example, some activities are considered more masculine or more feminine. Similarly, the programs that people watch on television or the news they read in periodicals or magazines affect how they socialize with others and come to understand what it means to be a man or a woman. As a culture changes, so do notions of what is masculine or feminine. The popular notions of the ideal male (or female) characteristics are largely determined by commercial interests, advertising, and other cultural fources. This is especially true for women. Advertisments in magazines and commercials on television tell us what it means, and how much it will cost to be a beautiful woman.

Perfection is portrayed at every stage in life - whether it is a beautiful doll little girls are given to play with or perfect-looking supermodels in fashion magazines. It is not a secret what is accepted and expected. Our expression of gender identity not only communicates who we think we are but also constructs a sense of who we want to be. We learn what masculinity and femininity mean in our culture and we negotiate how we communicate our gender identity to others (Martin, Nakayama 2011:97). As a result, nowadays mass media still uses gender stereotypes, basing on the assumption that they are well known to everyone and help the receivers to understand the content of the message delivered. It should be confessed that the differences between male and female roles are smaller today, however, mass media perpetuates traditionally and socially determine gender stereotypes. Though people are aware of the unequal representation of certain social groups in any type of mass media, it is hard to remain objective and insensitive to its influence.

The portrayal of women in advertising is an issue that has received a great deal of attention through years. It has been criticised for stereotyping women and falling to recognize the changing role of women in our society. Critics have particularly argued that advertising often depicts women as preoccupied with beauty, household duties, and motherhood or shows them as decorative objects or intriguing figures. Portrayals of women in television and print advertising have emphasized lack of intelligence and credibility for high levels of efforts. According to S. Craig's research, women can be presented in commercials in several ways. The first one is the most popular: a housewife who is obsessed by a steam on a new tablecloth or a woman whose main problem is lack of ideas for dinner. The other examples are less traditional, however, they are still stereotypical. One more type is a woman whose major concern is to preserve her beauty, so she presents a very healthy life style: she is physically active, uses a wide range of body and facial cosmetics. It should be noticed that one can observe mainly the presence of very thin actresses in this type of commercials, which can lead to the idea that only thin women can be considered an object of beauty. As a result, many female receivers fall into the obsession with their weight, which sometimes can have negative effects (Craig and Emerson 2000:65).

Advertising messages about women convey the idea that a woman's place is in the home, women do not make important decisions or do important things, they prompt us 
that women are dependent and need men's protection, and men regard women primarily as beautiful objects. Advertisements have consistently confined women to weak, childish, dependent, domestic, irrational, subordinate creatures, the producers of children and little else compared with men. Courtney and Lockeretz examined images of women in magazine advertisements. They reported the following findings: women were shown as dependent on men's protection, they were most often shown in ads for cleaning products, food products, beauty products, drugs, clothing and home appliances. Males were most often shown in ads for cars, travel, alcoholic beverages, cigarettes, banks, industrial products, entertainment media, and industrial companies (Courtney, Lockeretz 1979:92-95).

It seems that since then a lot should have been changed. However, the later researches have shown two opposite tendencies. According to one pole only few changes occurred. The view is grounded on the idea that perhaps advertising has this powerful role: to depict women not necessarily how they actually behave, but rather, how we think women behave. Furthermore, according to E.Goffman, this depiction serves the social purpose of convincing us that this is how women are, or want to be, or should behave. On the other hand, one cannot overlook the fact that there has been a revolutionary change in the workplace and in society since women began to come into the workforce. Women nowadays are not only gaining ground in workforce participation, but arealso filling positions once held primarily by men. If women have changed and if society has therefore been altered, then it could not but be reflected in ads as the demands of the society have consequently changed (Goffman 2009).

Whatever effort women put to take men's positions in various spheres, one thing is certain; there exist vast differences between their behaviors and the way society perceives them. As already mentioned, the concept of beauty is assumed to be one of the central issues in women's lives. The beauty role - the importance of appearing attractive in public, of maintaining standards, of encouraging male attention, is said to become a central preoccupation for girls and remains a concern for women for much of their lives, if not all their lives (Barthel 1988:10). For example, the advert of Palmolive Soap, published in 1950, depicts a naturally beautiful, tall, slender woman wrapped in a towel. From the modern perspective she would be considered rather old-fashioned, especially the way her hair is pulled back and the bow tied in it. Another feature which divulges its being out-of-date is the overuse of the text which is a rare thing among modern ads. A full paragraph explains how doctors approve of the beauty soap and how it can help one's complexion. The ad has little angels around the woman and the bar of the soap. Next to each angel is a description of the soap: Fragrance...for Daintiness, Mildness...for Loveliness, Purity...for Gentleness, Bath size...for Thriftiness. Use only Palmolive to give your skin this lovely charm... All over! The wording Daintiness, purity, gentleness, mildness, loveliness alongside with little cheerful cherubs conveys the message that a woman should be exactly that: a little smiling, mild angel. The language of the ad can also be described as "mild and gentle". The nouns are mostly formed on the basis of adjectives, like dainty-daintiness, mild-mildness, lovely-loveliness pure-purity, thrifty-thriftiness, gentle-gentleness, which create some light, airy atmosphere. 
R. Lakoff (2004) attempted to establish features which distinguished women's language from men's language. And one of the linguistic features she singled out was the use of "empty adjectives". These are adjectives that express feelings with no significant meaning. It is argued that this special type of adjectives, distinct from neutral adjectives, is characteristic of only women's language. Among them R. Lakoff also listed adjectives like lovely, charming, divine. This advert of Palmolive makes use of this type of adjectives. Here are some more examples taken from Elle women's magazine:

Get Gorgeous Hair and Glowing Skin for Good!

The best hair products for shiny, oh-so-voluminous locks starting from the roots.

It's nothing but good hair days ahead this winter with these amazing hair care products.

Get gorgeously glowing this Valentine's Day. Beauty tips for perfect eyebrows.

Though these empty adjectives are believed to express feelings with no significant meaning, they seem to have the power of "imparting certain sense of confidence"; they help the female consumer to imagine herself almost perfect and attractive. These empty adjectives and adjectives in general, add some more emotional coloring and contribute to the overall creation of the image. So, we may conclude, from what has been said, that the ad is full of feminine features from both linguistic and extra-linguistic perspective.

The next linguistic feature we are going to discuss seems to have the same property and ability. The feature suggested by R. Lakoff and reflected in the "feminine" commercials are the intensifiers - linguistic means that make no contribution to the propositional meaning of a clause but serve to enhance and give additional emotional context to the word they modify: Mohair is our newest soft wear program: impressively soft impossibly bright and extraordinarily user-friendly.

The examples discussed above come to state a rather disputable view - women are too much concerned with their appearance and beauty. According to stereotypical views, that is just the proper way she should behave. Women are relationship oriented, and look for commonalities, their conversational style is described as consensus-building. In case of women consensus means thinking alike, being in agreement, being the same. This idea of "grouping into a team and being similar" is expressed in advertisements as well.

Your friends use Mary Kay, and you? Only Mary Kay and Women! Dermatologists have put something unusually strong in this skin cleanser. Dove. Their trust. Women trust.

The advertisement adduced comes to illustrate the point that women have created their own separate world where they speak of things which they all use and here they may share their experiences and give advice to others. For example, the advert of Mary Kay suggests that a girl use the product as her friends have already tried it. So her friend's opinion can serve a kind of guarantee for her. However, it seems there is another motif hidden under the claim "your friends use Mary Kay", the so-called "motif of jealousy". 
The ad seems to have a subtext which says; "your friends already possess the product, so hurry and get one for you if you do not want to fall behind them".

Your friends will want to look at it. You won't even want to take it off to shower.

Years later babies will want to touch its light. Little girls will ask to try it on. And long after everything has changed, you'll look down at it and realize nothing has.

Lately certain commercials targeting women speak (not always directly) of the possibility of achieving the external beauty through the inner one. The concept of the inner beauty is believed to be closely connected with nature and with the harmony of it. So very many advertisements state the product's relation with nature. For example;

AVENDA: The art and science of pure flower and plant essences.

For Lancôme, beauty goes far beyond appearances. Beauty is an emotion reflected on the surface of the skin. An awakening of the senses, a harmonious connection between the mind, body and soul.

Femininity in the last ad is expressed through the use of the words flower, plant which seem to be rare things in adverts designed for men unless they are used with reference to women. In the commercials targeting men the concept of nature is basically used with reference to medicine. Perhaps the fact that women are portrayed closer to nature is hidden behind the prototypical perception of nature as a woman. The associations of women with nature are reflected in languages as well. For example in Latin, Italian, French, Russian or Spanish the word nature is gendered as female: la natura, la nature, priroda, la naturaleza, etc. Besides, woman and nature share the same characteristic features giving birth and providing the balanced life cycle.

The concept of infinity is expressed in the ads of cosmetics as well where it stands as an indicator of the reliable quality of the product. The advertisements of Estee Lauder and Max Factorassert:

Lauder lipstick makes lipfinity. Max Factor Lipfinity Colour and Gloss is an innovative double ended Lipstick which gives a depth of multitonal colour and shine for an eye catching look that lasts up to10 hours.

Here the combination of lip + infinity results in an interesting neologism lipfinity which seems to promise to entirely meet the women's demands of having long lasting color on their lips which would not fade as soon as they eat or drink something.

Women targeting advertisements can freely "play with different colors" creating new shades: 
First we doubled the color, then we doubled the wear, for lipcolor that's made to last. And added shimmering reflectants that give your lips dramatic depth. In fifteen shades that will make a lasting impression. Double Color Everlasting Lipstick. Non- stop color in 15 shades. From Petal Petal to Honey Honey.Estee Lauder Lips.Buttery yellow, white hot and honey hues ruled the spring runways. Our expert shares five tips on how to create - and maintain-the perfect shade...

The adverts represent a very interesting interpretation of different hues of colors which probably would be better perceived by women-consumers. Generally advertisements designated for women are much more colorful not only from the linguistic perspective.

Though in the course of time the image of the "newwoman" has undergone a number of changes, there has always been a kind of concern on women's not losing their femininity. Nowadays we may say that women have mostly succeeded in keeping the balance between traditional femininity and traditional masculinity. In advertisements passive, feeling-based adjectives and verbs are now replaced by lively, energetic and "actionrequiring" words which are considered to be men's property. The woman is encouraged to liberate herself, to be free; she is provoked to take her life in her own hands and to set up her own rules for the game.

Take control of your life: make him fall for you.

Nowadays you have to have brains as well as beauty.

Love me! Smashbox's new "Love Me" lip gloss range is funky, fresh and full of street cred.

Male stereotypes are quite different. The first model is "a real man", athletic, successful, professional seducer with a nice young lady by his side. The other type is less popular and presents men devoted to their families who can save enough time for them. Men are rarely presented during household activities. And if they are, it is rather a satirical image or they appear as experts and they are the ones who advise women how to to do things. On the whole, men are generally shown more knowledgeable, active, aggressive and instrumental than women. Nonverbal behaviours involving dominance and control are associated more with men than women. Advertisments directed towards children have also been shown to feature more boys than girls, to position boys in more dominant, active roles. Here are some examples to illustrate the points mentioned:

For the men in charge of Change. (Fortune buisness Magazine)

Try Nivea for Men Energizing Face Scrub, a hardworking face scrub for hardworking men. (Nivea for Men)

It is for you. Buy the car. Own the road. (Pontiac Grand Am) 


\author{
It's not your car. It's not your friends. It's not your job. It's your watch \\ that says most about who you are. (Seiko Watch)
}

The language of ads becomes more expressive with the help of tropes and figures of speech which provide the stylistic effect of advertisements; the use of tropes makes the language of advertisements unique, original, consequently natural. The most frequently used tropes to denote feminine and masculine features include metaphor, metonymy, hyperbola, epithet, simile, personification, etc. Epithets are often used with reference to those products which would "flatter" the consumer: cosmetics, perfume, products which offer luxury, etc. Epithets are to be extraordinary and, the more unique they are, the better they are remembered. For example:

Hair care is war/fight. Hair is under attack. The environment, heat styling, colouring and bleaching can all take their toll. Paul Mitchel fight back with new Super - a 3 part strengthening system for your hair. (Paul Mitchel Luxury Hair Care)

Vital Oils are high quality essential oils infused into pure, skin-softening organic apricot kernal oil. Preservative and colour-free, with nosynthetic perfume, the results are out-of this world aromas. With names that conjure the atmosphere they help to create. Choose from Restoring Comfort, reviving Harmony and sensual Bliss.

Similes are often used for introducing something unknown through something familiar. In advertising they are basically used for original sounding, for example, Swarowsky. Pure like love. Metaphors, as means of figurative language, are widely used in advertising because they can arouse and enliven the consumer's imagination, and represent an effective means to create brand associations and enhance persuasion. In advertising metaphors have the following functions: firstly the metaphor is considered to be "the material" through which the essence or basic idea of an ad is conveyed. One of the specific features of human mind is that an idea is better memorized in case it takes a metaphoric form. And, secondly, metaphor gives birth to new ideas and enforces the inner motivation. It influences indirectly and, what is more interesting, it reduces the level of criticism in consumer's mind with reference to advertising: it is difficult to contradict one's own ideas and associations (Bernadskaya 2008:67).

When used in advertising, metaphors create a picture in consumers' minds and tap into meaning that is shared both by the advertiser and the consumer. Metaphors may not accomplish their desired objective, however, if they are complicated or too abstract. Imposing certain feature that is typical of humans on a product may leave an impression as if the product is a part of our life. This is why personification is used in the advertisement of Geox shoes where the product is endowed with human ability to breathe: Geox Shoes that breathe or Baon Clothes with temper. Metonymy involves the substitution of an aspect of a product, thing or person for the thing itself, such as the crown representing the Queen. The Sunday Times is the Sunday Papers is a form of metonymy, trying to 
get the brand to stand and represent the entire product group (Brierley 2002:147). Hyperbole very often seems to be an indispensable part of advertising. It is necessary for the psychological influence as it exaggerates certain qualities of this or that object or event and underlines the uniqueness of the product (Blackest Black from Great Lash). The following example shows how the producers use certain objects metaphorically for creating a symbolic effect in consumers' minds.

Now get extremely big, way-out-there lashes that defy reality. E-long extends natural lashes to supernatural lengths - up to 50 percent longer. Super brush separates, defines and lengthens beyond belief. It's great to exaggerate.

The text of any advertisement is thought over thoroughly and delicately as each sentence, each word can be the key to any product's success. In this sense a great significance is attached to the ability of communicating correctly with both target groups of people and target individuals (Berdishev 2008:76). The right knowledge of the communicative process and its main techniques can be effective and can lead to the desired results. The importance given to the linguistic means used in advertisements, allows us to conclude that advertising occupies a special position in the problems related to the development of modern society. Advertising deals with ideas, attitudes, and values. It is an interesting issue of discussion from the psycholinguistic perspective, as first and foremost, it is closely connected with the art of speech, with the art of persuasion.

Commercials are powerful tools used for creating and shaping opinions, as well as forming proper choices. Texts of advertisments contain the prevailing characteristics of the objective reality, therefore stereotypes are very often used in the commercials as one of the most popular techniques of persuasion. It is evident that advertising is a huge and pervasive industry: it has a powerful effect that goes well beyond the purpose of selling products to consumers, it affects our culture and our views, therefore it is extremely persuasive. Consumer advertising most commonly associates products with symbols that exemplify values, feelings, prestige, status, power, achievement or just plain pleasure. The effect of gendered differences is apparent; gendered advertising beliefs, attitudes, values and consumer behaviour exist, therefore advertisers recognize them, understand them, and use them to design gender specific advertisments.

\section{References:}

1. Berdishev, S.N. (2008) Reklamni tekst. Metodika sostavleniya i oformleniya. M.: Dashkov i K.

2. Belch, G.E. and Belch, M.A. (2001) Advertising and Promotion: An Integrated Marketing Communications Perspective. San Diego State University.

3. Bernadskaya, Yu.S. (2008) Tekst v reklame. M.: Yunitti-Dana.

4. Brierley, S. (2002) The Advertising Handbook. Canada: Taylor \& Francis Group. 
5. Courtney, A. \& Lockeretz, S. (1971) A Woman's Place: An Analysis of the Roles Portrayed by Women in Magazine Advertisements. // Journal of Marketing Research, Vol. 8. Cambridge: Harvard University Press.

6. Craig, S. and Emerson, R. (2000) Feminist Media Criticism and Feminist Media Practices. // The Annals of the American Academy of Political and Social Science.

7. Goffman, E. (1978) Gender Advertisements. Cambridge, MA: Harvard University Press.

8. Lakoff, R.T. (2004) Language and Woman's Place: Text and Commentaries. New York: Oxford University Press.

9. Lee, M.; Johnson, C. (2005) Principles of Advertising: A Global Perspective. NY: The Haworth Press.

10. Talbot, M. (2010) Language and Gender. Cambridge: Polity Press.

11. Martin, J.N.; Nakayama, Th.K. (2011) Experiencing Intercultural Communication (An Introduction). New York: NY.

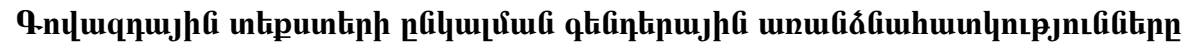

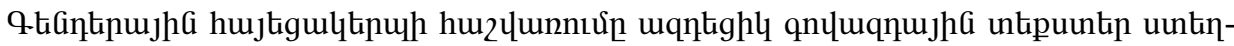

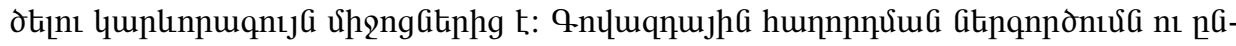

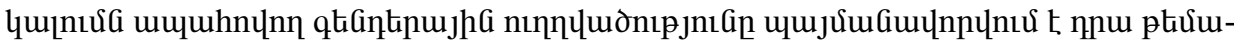

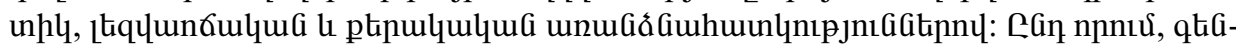

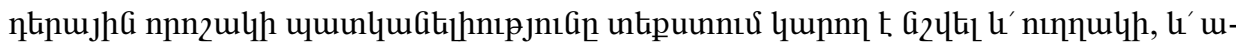

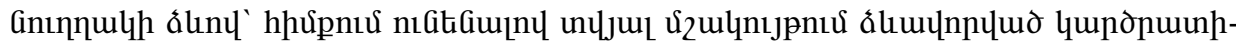

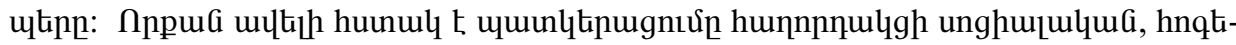

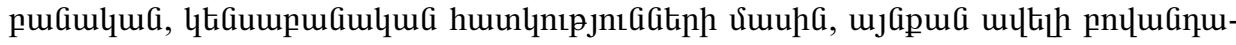

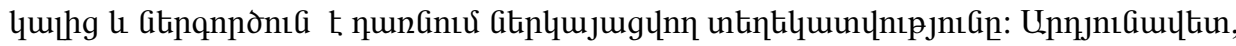

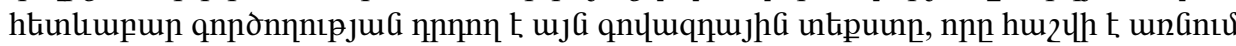

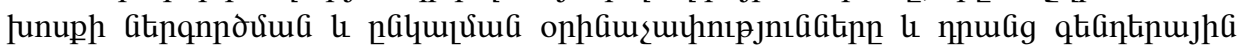

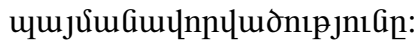

